\title{
Análisis de los Efectos de la Ordenación Forestal en 30 Años. Caso del Bosque Mediterráneo de la Región de Valparaíso Chile
}

\author{
Cruz, Pablo ${ }^{1 *}$; Carrasco, Bárbara ${ }^{2}$ y Bustos, Gabriel ${ }^{3}$. \\ ${ }^{1}$ Consultor. Ing. Forestal. Doctor Ciencias Agrarias y Forestales. tacora1@gmail.com \\ ${ }^{2}$ Consultor. Licenciada en Ciencias de los Recursos Naturales Renovables. bcarrascomascayano@gmail.com \\ ${ }^{3}$ Consultor. Licenciado en Ciencias de los Recursos Naturales Renovables. gabriel.bustos@ug.uchile.cl \\ *Autor para correspondencia
}

DOI: https://doi.org/10.52904/0718-4646.2017.469

Recibido: 06.04.21; Aceptado: 20.04.21

\begin{abstract}
RESUMEN
En este estudio se analizan los efectos que tendría el modelo forestal sostenible aplicado al bosque mediterráneo en el centro de Chile. Se seleccionó como estudio de caso un tipo de terreno de 900 hectáreas y 365 hectáreas de bosque, cuyo plan tiene dos años de ejecución del primer plan decenal. Se simuló la ejecución del plan durante treinta años en adelante y se comparó con la condición de no plan para el mismo período. La comparación se realizó con respecto a la captura del nivel de $\mathrm{CO}_{2}$ eq y los índices del paisaje efecto de borde y fragmentación. La condición sin plan fue simulada con el mismo bosque, sujeto a la tasa de deforestación publicada por la Estrategia Nacional de Cambio Climático (ENCCRV).

En treinta años sería posible aumentar el bosque sin efecto borde en un 95\%, y el número de fragmentos se reduciría en un $74 \%$, en comparación con la condición inicial. El escenario sin plan reduciría su bosque sin bordes en un $10 \%$ y aumentaría su fragmentación en un $274 \%$. Estos efectos se lograrían con la forestación. La captura de $\mathrm{CO}_{2} \mathrm{eq}$ con plan alcanzaría un $108 \%$ más que la condición sin plan en treinta años, en los que el $93 \%$ se debería a la gestión y solo el $15 \%$ a la forestación. La ganancia en $\mathrm{CO}_{2}$ eq en treinta años debido al manejo costaría 7 US\$/t y la ganancia por forestación 15 $\$ U S / t$.
\end{abstract}

Palabras clave: Ordenación forestal, restauración del paisaje, nivel de referencia, bosque mediterráneo.

\section{SUMMARY}

This study analyzes the effects that the sustainable forest model applied to the Mediterranean forest in central Chile would have. A type of land of 900 hectares and 365 hectares of forest was selected as a case study, whose plan has two years of execution of the first ten-year planning plan. Execution of the plan for thirty years onwards was simulated and compared with the no-plan condition for the same period. The comparison was made with respect to the capture of the $\mathrm{CO}_{2}$ eq level and the indexes of the landscape edge effect and fragmentation. No-plan condition was simulated with the same forest, subject to the deforestation rate published by the National Climate Change Strategy (ENCCRV).

In thirty years, it would be possible to increase the forest without edge effect by $95 \%$, and the number of fragments would be reduced by $74 \%$, compared to the initial condition. No-plan scenario would reduce the no-edge forest by $10 \%$ and increase its fragmentation by $274 \%$. These effects would be achieved with afforestation. The capture of $\mathrm{CO}_{2} \mathrm{eq}$ with plan would reach $108 \%$ more than the condition no-plan in thirty years, in which $93 \%$ would be due to management and only $15 \%$ to afforestation. The profit in $\mathrm{CO}_{2} \mathrm{eq}$ in thirty years due to management would cost $7 \mathrm{\$ US} / \mathrm{t}$ and profit due afforestation $15 \$ \mathrm{US} / \mathrm{t}$.

Keywords: Forest management, landscape restoration, reference level, Mediterranean forest.

\section{INTRODUCCIÓN}

Chile oficializó su Estrategia Nacional de Cambio Climático y Recursos Vegetacionales (ENCCRV) en 2015 y contiene importantes aportes para establecer un marco de referencia a las acciones políticas nacionales que reduzca la deforestación y degradación de bosques (Ministerio de Agricultura, 2016). Uno de ellos es el diagnóstico de las causas de deforestación de bosques a escala nacional y las tres más importantes fueron los incendios forestales, el uso del ganado en los bosques y el manejo insustentable. 
Se entiende uso insustentable como la falta de criterios, tanto en la planificación como en la ejecución de las acciones sobre el bosque, que garanticen al menos el rendimiento sostenido.

Actualmente, solo se conoce un instrumento oficial que contiene reglamentaciones y restricciones al manejo, y que está definido en la Ley 20.283, Ilamado Plan de Manejo. Este instrumento es un permiso de gestión pública con un diseño que sirve a los intereses del Estado y efectivamente no recoge criterios de sustentabilidad ni de rendimiento sostenido (Rothermel, 2002; Cruz et al., 2005; Cruz et al., 2012; OTERRA, 2014). No existe en Chile otro instrumento oficial que regule el uso, ni tampoco, alguno diseñado para ayudar a los propietarios a manejar sus bosques.

El segundo importante aporte de la Estrategia (ENCCRV) es que el Estado compromete acciones directas para cada causal. Para la tercera causa, llamada manejo insustentable, se estableció el compromiso de incorporar el criterio de ordenación forestal en los permisos de gestión pública, con una meta de 70 mil hectáreas bajo ordenación forestal al año 2025. Indica como condición que las extracciones se ajusten a la tasa de aprovechamiento sostenible y que sean de largo plazo.

Cruz (2020) define la ordenación forestal como un instrumento de planificación del uso del bosque cuando se persiguen tres objetivos: la permanencia del bosque, el mantenimiento de los beneficios que produce y la maximización de sus bienes y servicios. Un aspecto intrínseco es que la ejecución de las acciones en el largo plazo logre verdaderamente que el bosque persista y mejore en su estado de conservación, amén de los beneficios que entregó en cada periodo.

Sin bien el país ya cuenta con diversas experiencias de Ordenación Forestal (CONAF, 1997; Cruz et al., 2001; Rivera et al., 2002) la mayoría quedaron en la escritura del informe y no se ejecutaron, por tanto, casi no existen experiencias aplicadas que consultar.

Gracias a los aportes de la Agencia de Sustentabilidad y Cambio Climático, CONAF y un grupo de propietarios de bosques, fue posible diseñar un modelo de ordenación forestal aplicado a bosques mediterráneos de la región de Valparaíso, del que se han cumplido tres años de ejecución.

Este proceso ha entregado una contundente experiencia que motivó estudiar la proyección de los efectos de la ordenación forestal en dos sentidos; del punto de vista de los objetivos de permanencia y mejora del bosque, y del punto de vista de las ganancias de estas mejoras en el marco de reducción de emisiones de gases de efecto invernadero (GEI).

Un requisito metodológico cuando se evalúa la evolución del estado de conservación de bosques es escoger instrumentos de análisis que cuantifiquen objetivamente el cambio e idealmente ofrezcan métrica de los cambios.

A escala de paisaje, vale decir considerando un área con más funciones que meramente el bosque, pueden utilizarse índices del paisaje que permiten establecer métrica del estado de conservación a través de información espacial (Del Río et al., 2003; Lindenmayer et al., 2006).

La superficie de borde en el bosque, por ejemplo, es un índice que propone que bosques con un núcleo sin efecto de los bordes mantienen su homeostasis y alta resilencia (Murcia, 1995). Como índice del paisaje, es potente debido a que cuantifica objetivamente y a que la relación entre lo medido y el efecto es evidente.

El grado de fragmentación del bosque, a su vez, como índice del paisaje propone que a mayor cantidad de fragmentos y menor tamaño de ellos menor será el grado de conservación del bosque (Vogelmann, 1995). Este índice tiene las mismas cualidades que el anterior.

Otros índices, son complejos de analizar y usan escalas adimensionales difíciles de interpretar y resultan poco prácticos para evaluar el cambio en el estado de conservación ecosistémico (Cruz y Gorospe, 2019).

Sin embargo, los índices del paisaje son insensibles al cambio en el estado de conservación dentro de cada fragmento y se relacionan más bien con el cambio en la estructura del bosque, la composición, la tasa de procesos ecosistémicos y el nivel adecuado de las perturbaciones naturales (Lindenmayer et al., 2006; Schulte et al., 2006). 
Un enfoque pragmático propuesto por Cruz (2020) para medir el estado de conservación de bosques es su contenido de biomasa, dado que el mayor componente de la masa del ecosistema se concentra en los árboles, es fácil de medir, existe vasto conocimiento respecto de la relación entre el nivel de masa y el estado de conservación, entre otros atributos.

Aceptándose la biomasa como estimador del grado de conservación, se suma la enorme utilidad de permitir realizar una conversión directa al más importante parámetro en el que se mide el nivel de referencia usado en la Estrategia REDD+, que es el contenido de $\mathrm{CO}_{2} e q$, gracias a los estándares aceptados por el IPCC (2006).

Un enfoque similar se usó en el Nivel de Referencia de Emisiones Forestales (CONAF, 2016), en que se definió el nivel de degradación del bosque (degradación como inverso de conservación) a partir de una guía de densidad general.

En este caso, la variable es la relación DAP/área basimétrica/densidad, que, si bien está relacionada a la biomasa, tiene mayor grado de complejidad.

Este enfoque permite alinear los resultados empíricos del manejo con la estrategia de modelar el secuestro de carbono por el uso del bosque, como lo proponen Masera et al. (2003).

\section{OBJETIVOS}

El objetivo de este estudio es analizar los efectos de la Ordenación Forestal aplicada, en una proyección de 30 años en bosques mediterráneos de la región del Valparaíso, Chile. Para el análisis se usarán dos criterios.

El primero la variación del paisaje, evaluado con índices del paisaje efecto borde y fragmentación. El segundo la variación en la captura de $\mathrm{CO}_{2} e q$, derivado de la acumulación de biomasa.

\section{MATERIALES Y MÉTODOS}

\section{Escenario con Plan: Modelo de Ordenación Forestal}

La proyección de escenarios fue construida usando los resultados del proyecto manejo sustentable del bosque nativo mediterráneo, APL I. (ASCC, 2016), que consistió en la elaboración de un modelo de ordenación forestal para los bosques mediterráneos de 4 predios en la provincia de Valparaíso, que sumó una superficie total de 2.800 ha.

El modelo de ordenación forestal ha sido descrito en Cruz (2020) y sus aspectos esenciales son:

- La propuesta es integral, incluye todo el bosque de la propiedad.

- Las extracciones de biomasa están sujetas a máximos prediales determinados por el crecimiento y el grado de degradación del bosque. Estos máximos son llamados parámetros de ordenación forestal.

- La planificación es a largo plazo, se detallan las acciones y se definen áreas de intervención para 10 años (primer periodo de planificación).

- Se asume que el bosque mediterráneo está degradado, por tanto, solo se proponen dos tipos de actividades silvícolas:

Resalveo: Consiste en la reducción de vástagos que crecen sobre una cepa para recuperar el balance de agua entre la raíz y la masa aérea (Figura 1). En la corta se favorecen los pies mayores, eliminando vástagos de menor tamaño. Esta actividad se aplica a zonas con cobertura igual o mayor a $50 \%$.

Enriquecimiento: Consiste en plantaciones entre fragmentos de bosque con el objetivo de recuperar áreas que se unirán a los originales en el futuro. Se aplica a zonas con cobertura menor a $50 \%$. 

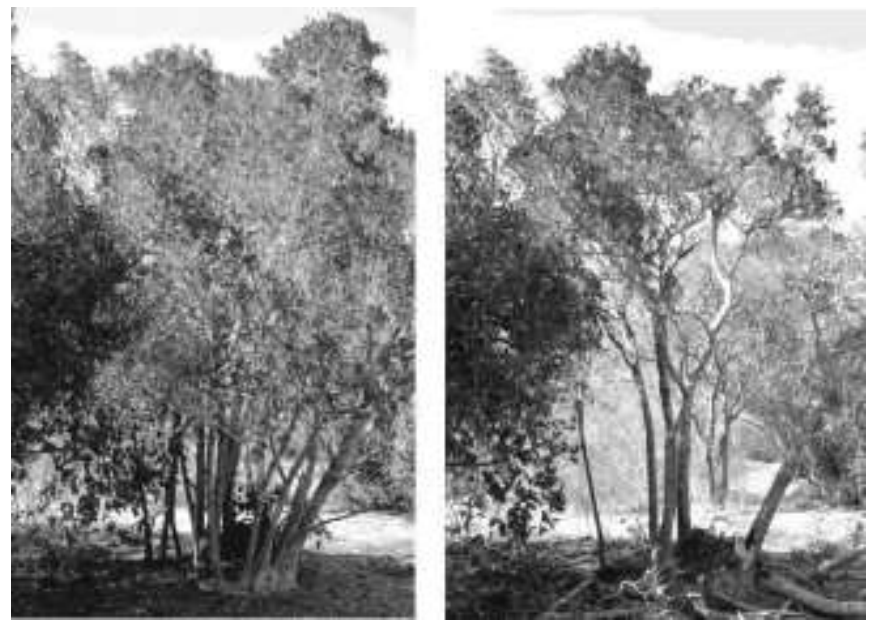

(Fuente: Cruz, 2020)

Figura 1. Resalveo Aplicado a un Árbol de Boldo

\section{Predio Escogido como Caso de Estudio}

Para este estudio se seleccionó uno de los predios ubicado en la comuna de Casablanca (Figura 2), cuya superficie es de 909 ha totales (Cuadro 1). Por la definición legal de bosque (Ministerio de Agricultura, 2008) 695 ha serían bosque con $10 \%$ o más cobertura arbórea, pero ecosistémicamente, para este estudio se consideró bosque solo aquel que tuviera más de $50 \%$ de cobertura, siendo el resto considerado matriz, es decir un ecosistema alterado.

Cuadro 1. Proyección de las Acciones Silvícolas para 30 Años Asumiendo el Mismo Ritmo Determinado en el POF del Predio (para 10 Años)

\begin{tabular}{|c|c|c|c|c|c|c|c|}
\hline \multirow[t]{2}{*}{ Tipo de cobertura } & \multirow{2}{*}{$\begin{array}{l}\text { Sup } \\
\text { (ha) }\end{array}$} & \multicolumn{4}{|c|}{$\begin{array}{c}\text { Resalveo } \\
\text { Proyectado } \\
\text { (ha) }\end{array}$} & \multicolumn{2}{|c|}{$\begin{array}{c}\text { Enriquecimiento } \\
\text { Proyectado } \\
\text { (ha) }\end{array}$} \\
\hline & & Anual & $\begin{array}{l}\text { Primero } \\
\text { (año 12) }\end{array}$ & $\begin{array}{l}\text { Segundo } \\
\text { (año 24) }\end{array}$ & $\begin{array}{l}\text { Tercero } \\
\text { (año 30) }\end{array}$ & Anual & $\begin{array}{c}\text { En } \\
30 \text { años }\end{array}$ \\
\hline Bosque & 695 & & & & & & \\
\hline Manejo Resalveo & 356 & 30 & 356 & 356 & 180 & & \\
\hline Enriquecimiento & 339 & & & & & 5 & 150 \\
\hline
\end{tabular}

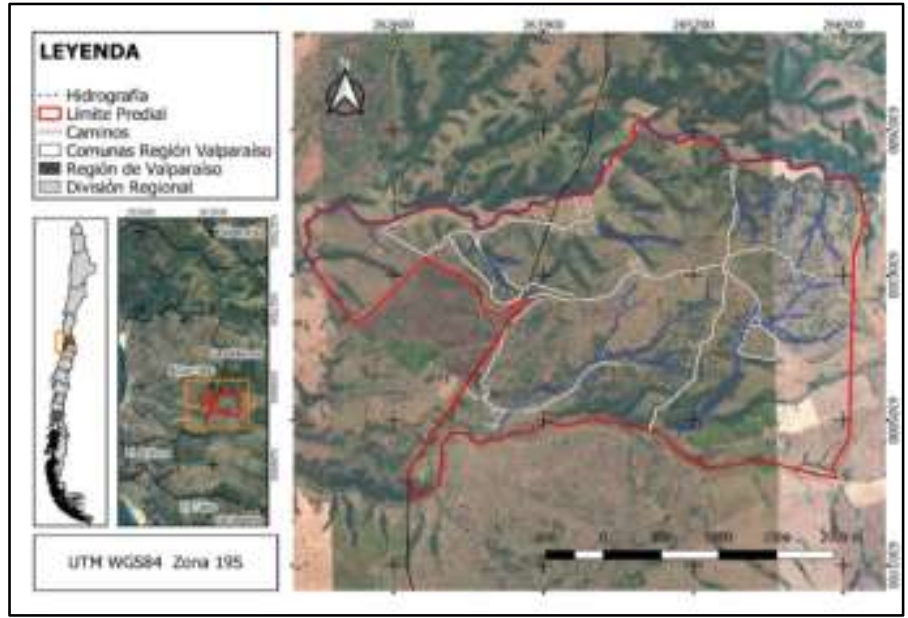

Figura 2. Ubicación del Predio en Zona del Acuerdo de Producción Limpia en la Región 
El modelo descrito aplicado al predio escogido como estudio de caso propone ejecutar 30 ha/año de resalveo y 5 ha/año de enriquecimiento (Figura 3).

Para realizar la proyección a 30 años, se supuso que las acciones se aplicarían en el tiempo sin variación en superficie (Cuadro 1).

Cuando el resalveo cubriera toda la superficie de bosque (en el año 12), se iniciarían los segundos resalveos sobre rodales intervenidos inicialmente y de la misma forma los terceros, hasta alcanzar los 30 años de la proyección.

Considerando que el ciclo de corta máximo estimado para todo el bosque fue de 8 años, al aplicar un ciclo de 12 años, se propiciaría la acumulación de biomasa en los tres años adicionales.

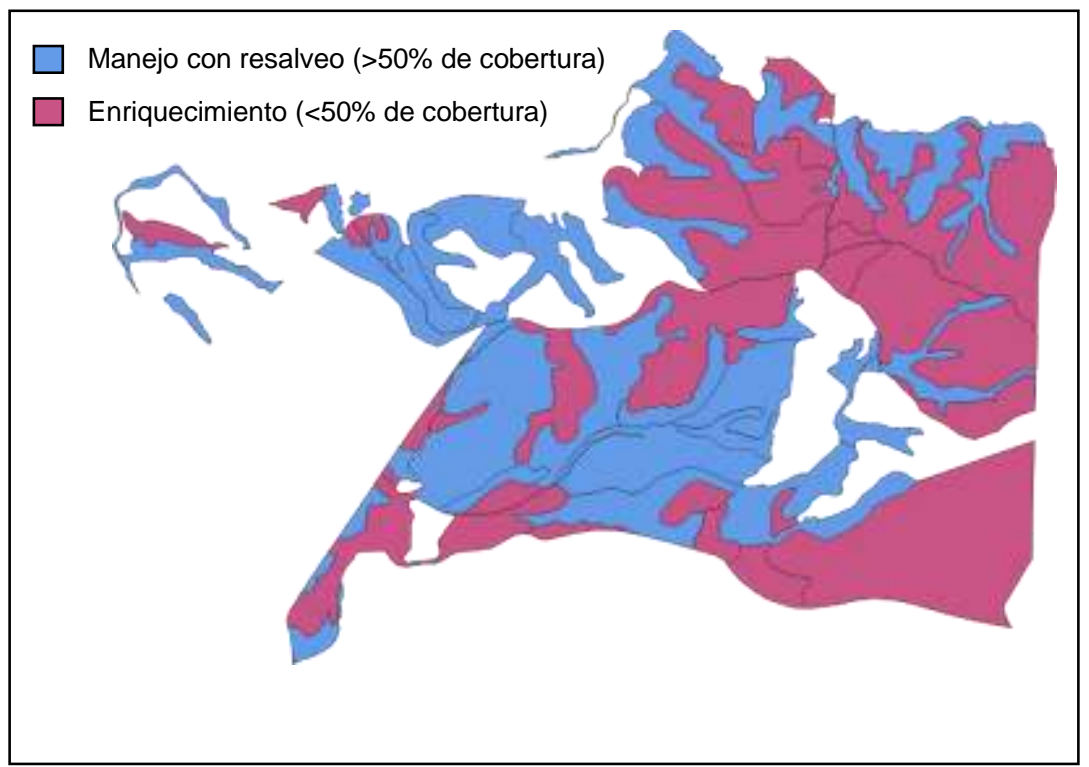

Figura 3. Áreas Involucradas en el Plan de Ordenación para Resalveo y Enriquecimiento

El enriquecimiento de 5 ha/año puede realizarse por más de 30 años dada la superficie disponible. En estas zonas enriquecidas solo se consideró un bosque establecido cuando su cobertura alcanza el $50 \%$, en consideración a los supuestos que definen bosque para este estudio.

Para definir el plazo para que las zonas enriquecidas alcancen dicha cobertura se analizó el aumento de cobertura de plantaciones de Quillay realizadas en la zona desde el año 2000.

Para esto se analizó la cobertura de 150 ha plantadas en 16 años (cerca de 10 ha de plantaciones por año), sobre las imágenes históricas de la plataforma Google Earth evaluadas el año 2019.

Los datos resultantes fueron usados para elaborar una regresión lineal entre cobertura/año de plantación, sobre la que se extrajo el año con cobertura igual a $50 \%$.

\section{Escenario sin Plan: Nivel de Referencia REDD+ Chile}

Se utilizó la tasa de cambio de cobertura de suelo que determinó la Estrategia Nacional de Cambio Climático y Recursos Vegetacionales (CONAF, 2016) para el bosque mediterráneo de la región de Valparaíso, correspondiente a un 0,39\% de deforestación anual de la superficie.

Esta tasa de deforestación fue aplicada al predio en estudio por 30 años.

Para la localización de la deforestación anual dentro del predio se estableció un modelo de asignación de probabilidad de deforestación basado en tres variables (Cuadro 2). 
Cuadro 2. Algoritmos del Modelo de Asignación de la Deforestación Establecido en la ENCCRV a un Caso Concreto de Estudio

\begin{tabular}{|c|c|c|}
\hline Variables & Algoritmos & Datos de entrada \\
\hline $\begin{array}{l}\text { Cercanía a los } \\
\text { bordes del } \\
\text { bosque }\end{array}$ & $P C_{m x}=\frac{\left(M_{i}-M_{\min }\right)}{\left(M_{\max }-M_{\min }\right)}$ & $\begin{array}{l}\text { PCmx: Probabilidad de deforestación del anillo i según } \\
\text { cercanía al borde }(\%) \\
\text { Mi: Cercanía al borde del anillo i }(\mathrm{m}) \\
\text { Mmin: Distancia del anillo más cercano al borde }(\mathrm{m}) \\
\text { Mmax: Distancia del anillo más lejano al borde }(\mathrm{m})\end{array}$ \\
\hline $\begin{array}{l}\text { Cercanía a } \\
\text { caminos }\end{array}$ & $P_{c}=\frac{\left(C_{i}-C_{\min }\right)}{\left(C_{\max }-C_{\min }\right)}$ & $\begin{array}{l}\text { Pc: Probabilidad de deforestación del anillo i según } \\
\text { cercanía a caminos (\%) } \\
\text { Ci: Cercanía a caminos del anillo de bosque i }(\mathrm{m}) \\
\text { Cmin: Distancia del anillo más cercano a los caminos } \\
(\mathrm{m}) \\
\text { Cmax: Distancia del anillo más lejano a los caminos } \\
\text { (m) }\end{array}$ \\
\hline $\begin{array}{l}\text { Tamaño del } \\
\text { fragmento de } \\
\text { bosque }\end{array}$ & $P_{t}=1-\left(\left(T_{i}-T_{\min }\right) /\left(T_{\max }-T_{\min }\right)\right)$ & $\begin{array}{l}\text { Pt: Probabilidad de deforestación del parche i según } \\
\text { su tamaño }(\%) \\
\text { Ti: Superficie del parche i }\left(\mathrm{m}^{2}\right) \\
\text { Tmin: Superficie del parche más pequeño }\left(\mathrm{m}^{2}\right) \\
\text { Tmax: Superficie del parche más grande }\left(\mathrm{m}^{2}\right)\end{array}$ \\
\hline $\begin{array}{l}\text { Probabilidad de } \\
\text { deforestación }\end{array}$ & $P_{d e f}=\frac{\left(P_{m x}+P_{c}+P_{t}\right)}{3}$ & $\begin{array}{l}\text { Pdef: Probabilidad de deforestación (\%) } \\
\text { Pmx: Probabilidad de deforestación por cercanía al } \\
\text { borde del bosque (\%) } \\
\text { Pc: Probabilidad por cercanía a los caminos (\%) } \\
\text { Pt: Probabilidad por el tamaño de parche }(\%)\end{array}$ \\
\hline
\end{tabular}

La cercanía al borde se aplicó dividiendo cada fragmento de bosque en anillos interiores paralelos al borde $25 \mathrm{~m}$ de ancho. El algoritmo del Cuadro 2, se aplicó a los anillos de cada fragmento para asignar una probabilidad de deforestación debida a la cercanía al borde. La cercanía a caminos se analizó dividiendo el bosque en un conjunto en anillos de $25 \mathrm{~m}$ de ancho equidistantes a los caminos. A cada franja se asignó una probabilidad de deforestación según el algoritmo del Cuadro 2.

La probabilidad de deforestación según el tamaño del parche supone que parches de menor tamaño tendrían mayor probabilidad de ser deforestados (Otavo y Echeverría, 2017). Así, cada fragmento tendrá una probabilidad de deforestación según su tamaño relativo respecto del conjunto, lo que se determina con el algoritmo del Cuadro 2.

Para combinar las tres variables y asignar una probabilidad al bosque de ser deforestado, se intersectaron las tres capas en una grilla vectorial de $25 \mathrm{~m}$ de lado, sobre la que se aplicó el algoritmo de probabilidad total del Cuadro 2 (Figura 4).

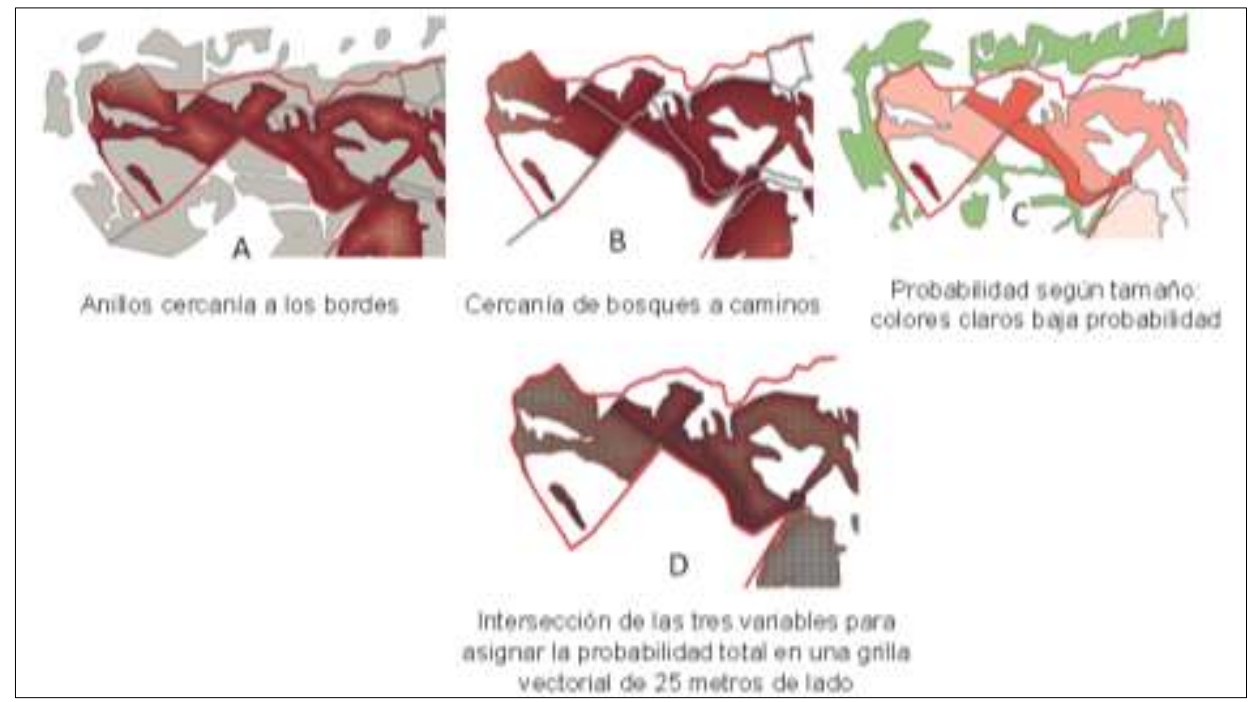

Figura 4. Aplicación del Modelo de Deforestación a un Caso de Estudio 


\section{Supuestos para Estimar los Efectos de la Ordenación Forestal}

Para asignar efectos de silvicultura y condición sin manejo a los escenarios fueron usados los reportes de seguimientos de ensayos de resalveos en la zona, instalados el año 2008 (Schulze et al., 2008), evaluados 7 años después de las intervenciones (Cuadro 3).

Cuadro 3. Resultados de las Intervenciones en Bosque Mediterráneo Después de 7 Años

\begin{tabular}{lccccc} 
& \multicolumn{4}{c}{ Año 2008. Edad del bosque 15 años (momento en que se instaló el ensayo) } \\
\hline & \multicolumn{2}{c}{$\begin{array}{c}\text { Densidad } \\
\text { (árb/ha) }\end{array}$} & $\begin{array}{c}\text { Área Basal } \\
\left(\mathbf{m}^{2} / \mathbf{h a}\right)\end{array}$ & $\begin{array}{c}\text { DMC } \\
\mathbf{( c m )}\end{array}$ \\
\hline Cond Iniciales & Inicial & Residual & Inicial & Residual \\
Parcela 1 & 7.120 & 2.110 & 27 & 8,3 & 6,9 \\
Parcela 2 & 8.398 & 2.110 & 12 & 8,3 & 4,3 \\
\hline
\end{tabular}

\begin{tabular}{|c|c|c|c|c|c|c|}
\hline \multirow[b]{2}{*}{ Testigo } & \multirow{2}{*}{$\begin{array}{c}\begin{array}{c}\text { Densidad } \\
\text { (árb/ha) }\end{array} \\
5.290\end{array}$} & \multirow{2}{*}{$\begin{array}{c}\begin{array}{c}\mathrm{AB} \\
\left(\mathrm{m}^{2} / \mathrm{ha}\right)\end{array} \\
17,0\end{array}$} & \multirow{2}{*}{$\begin{array}{c}\begin{array}{c}\text { DMC } \\
(\mathbf{c m})\end{array} \\
6,4\end{array}$} & \multirow{2}{*}{$\begin{array}{c}\begin{array}{c}\text { Mortalidad } \\
\text { Anual }^{*} \\
(\%)\end{array} \\
3,7 \\
5,3\end{array}$} & \multicolumn{2}{|c|}{$\begin{array}{c}\text { Crecimiento DAP } \\
\text { (cm/año) }\end{array}$} \\
\hline & & & & & $\begin{array}{l}-0,5 \\
2,1\end{array}$ & $\begin{array}{l}-0,07 \\
0,30\end{array}$ \\
\hline $\begin{array}{l}\text { Manejado (promedio) } \\
\text { Diferencias (\%) }\end{array}$ & $\begin{array}{c}2.984 \\
56\end{array}$ & $\begin{array}{l}25,0 \\
147\end{array}$ & $\begin{array}{l}10,3 \\
161\end{array}$ & $-5,9$ & $\begin{array}{l}3,4 \\
162\end{array}$ & 0,49 \\
\hline
\end{tabular}

Cuadro 4. Valores Escogidos para la Proyección a 30 Años en los Escenarios Con y Sin Plan de Ordenación

\begin{tabular}{lcc}
\hline Variable & $\begin{array}{c}\text { Con Plan } \\
\text { (bosque manejado) }\end{array}$ & $\begin{array}{c}\text { Sin Plan } \\
\text { (sin manejo) }\end{array}$ \\
\hline Crecimiento DAP (cm/año) & 0,49 & 0,3 \\
Mortalidad anual (\%) & 0,0 & 3,7 \\
\hline
\end{tabular}

La proyección del desarrollo del bosque se hizo con el método de proyección de tablas de rodal futuras de Reynolds et al. (1988), usando los niveles de crecimiento y mortalidad escogidos para la condición de manejo y sin manejo (Cuadro $\mathrm{N}^{\circ} 4$ ).

$$
x_{i, t+1}=\left(x_{i t}-\frac{c_{i} \cdot x_{i t}}{b}+\frac{c_{i} \cdot x_{i-1 t}}{b}\right) \cdot(1-m)
$$

Donde: $\quad \mathrm{x}_{\mathrm{i}, \mathrm{t}+1}$ : Densidad en la clase i en el año $\mathrm{t}+1$

$x_{i t}$ : Densidad en la clase $i$ en el año $t$

$c_{i}:$ Crecimiento diametral (cm/año)

b: Rango de la clase

$\mathrm{x}_{\mathrm{i}-1 \mathrm{t}}$ : Densidad en la clase $\mathrm{i}-1$ en el año $\mathrm{t}$

$\mathrm{m}$ : Tasa de mortalidad anual

Así, se usaron las tablas de rodal de cada rodal de bosque que se construyeron en el POF. Los rodales intervenidos se proyectan en el futuro con los datos Con Plan desde el año de su intervención hacia el futuro. Todos los rodales sin intervención se proyectaron con los datos Sin Plan.

\section{Evaluación del Estado de Conservación del Bosque en Cada Escenario}

\section{- A Escala de Paisaje}

La variación del estado de conservación a escala de paisaje fue evaluado con dos índices del paisaje, nivel de fragmentación y efecto borde. La comparación se realiza aplicando los índices a dos momentos, el valor de los índices a 30 años Con Plan, respecto del valor de los índices en el momento inicial; valor 
de los índices a 30 años Sin Plan, respecto del valor de los índices en el momento inicial. Adicionalmente, para establecer los niveles máximos de conservación a escala de paisaje, fue construido el paisaje de referencia del predio (Figura № 5), según la propuesta de Cruz y Gorospe (2018), que consiste en crear teóricamente la cartografía del predio con todo el bosque recuperado. El paisaje de referencia permite establecer los máximos posibles de los índices para el caso de estudio.

\section{- A Escala de Bosque}

Las diferencias entre los escenarios con y sin plan de ordenación forestal a escala de bosque, se evaluaron en función de la variación en captura de $\mathrm{CO}_{2}$ equivalente $\left(\mathrm{CO}_{2} \mathrm{eq}\right)$.

Las transformaciones entre valores de masa, carbono y $\mathrm{CO}_{2}$ eq usadas fueron aquellas recomendadas por el Panel Intergubernamental de Cambio Climático (IPCC, 2003), que señalan los siguientes factores:

- De volúmenes de madera a masa, factor 0,5 (densidad estandarizada de la madera).

- De biomasa a carbono, factor 0,5 (contenido promedio de carbono en la madera).

- De carbono sólido en la madera a $\mathrm{CO}_{2} \mathrm{eq}$, factor $44 / 12$ respecto de los pesos moleculares de $\mathrm{C}$ y $\mathrm{O}$ respectivamente $(3,66)$.

- Adición de la biomasa de raíces como un 35\% de la masa aérea determinada.

\section{RESULTADOS}

\section{A Escala de Paisaje}

El paisaje de referencia indica que el predio podría tener 848 hectáreas totales de bosque, en 9 fragmentos con un tamaño promedio de 94 hectáreas (Figura 5). El bosque actual solo ocuparía el $42 \%$ de la superficie disponible para bosques.

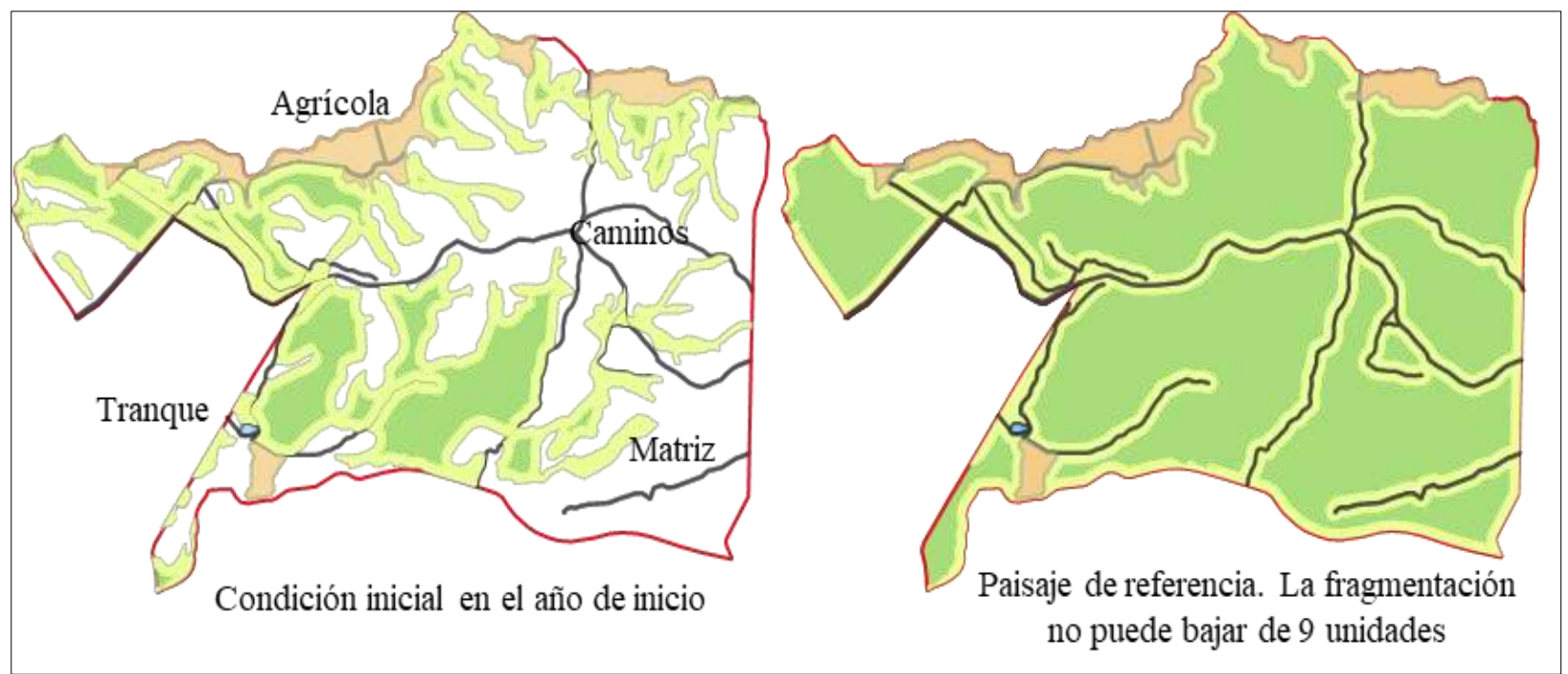

(Fuente: Cruz y Gorospe, 2019)

Figura 5. Construcción del Paisaje de Referencia de la Zona de Estudio

El análisis del plazo para que el enriquecimiento alcance un 50\% de cobertura fue establecido en 13 años (Figura 6 y Figura 7). 


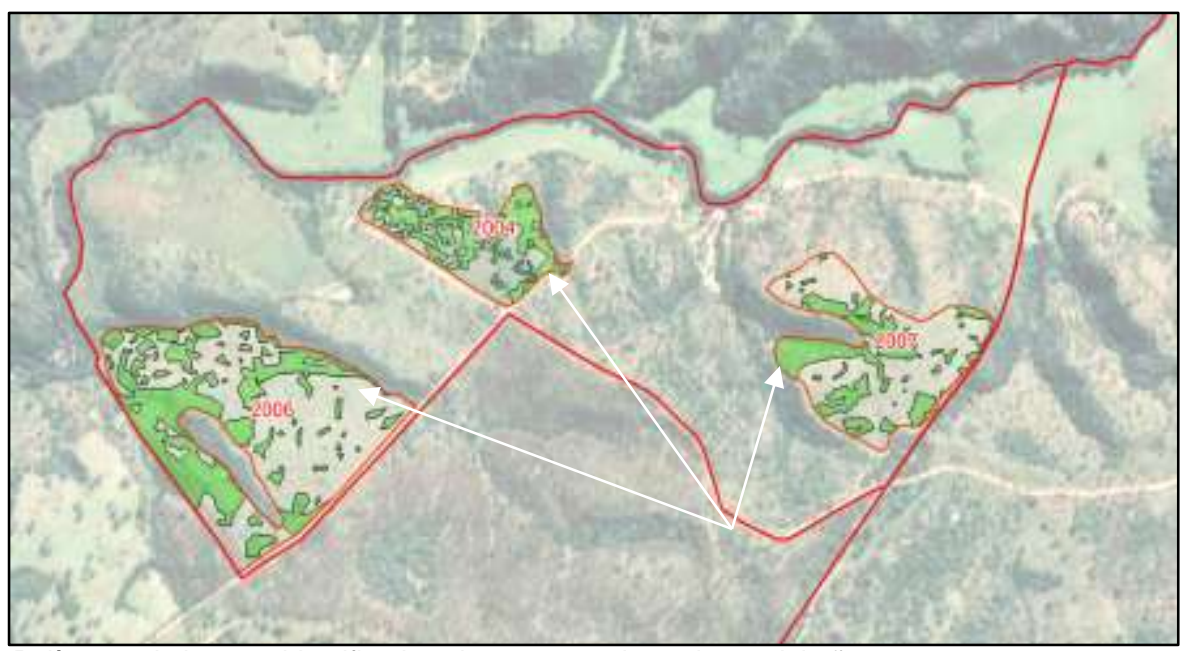

Polígonos de bosque identificados el 2018 para plantaciones del año 2004, 2006 y 2007

Figura 6. Determinación de las Coberturas en Plantaciones de Quillay de la Zona Usando Imágenes Históricas de Google Earth

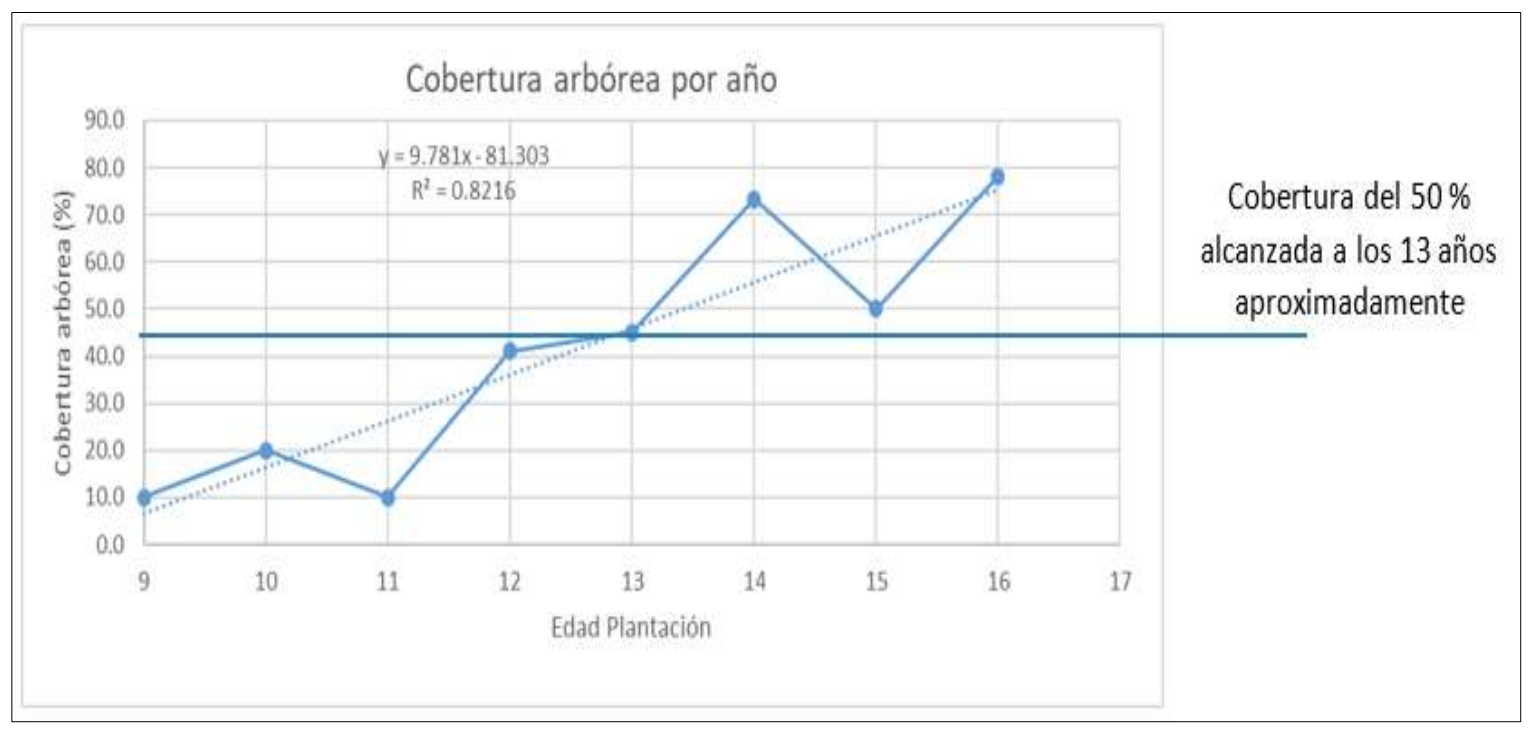

Figura 7. Regresión Simple Entre Año de Plantación y Cobertura en el Tiempo

Los efectos de aplicar las tasas de deforestación determinadas para el bosque mediterráneo en Chile por 30 años (Figura 8), significarían que la fragmentación del bosque aumenta 2,7 veces y el tamaño promedio de los fragmentos se reduciría a un tercio del promedio inicial (Cuadro 5, condición sin plan) y solo sería un 6,4 \% del tamaño promedio estimado para el paisaje de referencia.

En el escenario con plan de OF, en cambio, se reduce la cantidad de fragmentos y, a su vez, aumenta el tamaño promedio, debido al efecto combinado de evitar la deforestación y el enriquecimiento de 5 ha por año, como indica el POF.

Comparado con la referencia, la aplicación de la OF permite aumentar la superficie promedio de cada fragmento desde un $20 \%$ hasta un $33,8 \%$ respecto del tamaño promedio ideal que tienen los fragmentos de la referencia. 
Cuadro 5. Comparación de la Fragmentación Entre el Escenario Con Plan y Sin Plan de OF en 30 Años. Se Contrastan Datos con el Paisaje de Referencia

\begin{tabular}{lcccccc} 
& \multicolumn{3}{c}{$\begin{array}{c}\text { Fragmentos } \\
\text { (N }{ }^{\circ}\end{array}$} & \multicolumn{2}{c}{$\begin{array}{c}\text { Tamaño Promedio } \\
\text { (ha) }\end{array}$} \\
\cline { 2 - 6 } & Con Plan & Sin Plan & Referencia & Con Plan & Sin Plan & Referencia \\
\hline Período & 19 & 19 & 9 & 18,75 & 18,75 & 93.95 \\
Año 0 & 19 & 60 & & 18,75 & 5,71 & \\
Año 10 & 18 & 58 & & 21,87 & 5,68 \\
Año 20 & 14 & 52 & 31,79 & 6,09 \\
Año 30 & 74 & 274 & & 170 & 32 \\
Variación respecto del año inicial (\%) & 74 & & & & \\
\hline
\end{tabular}

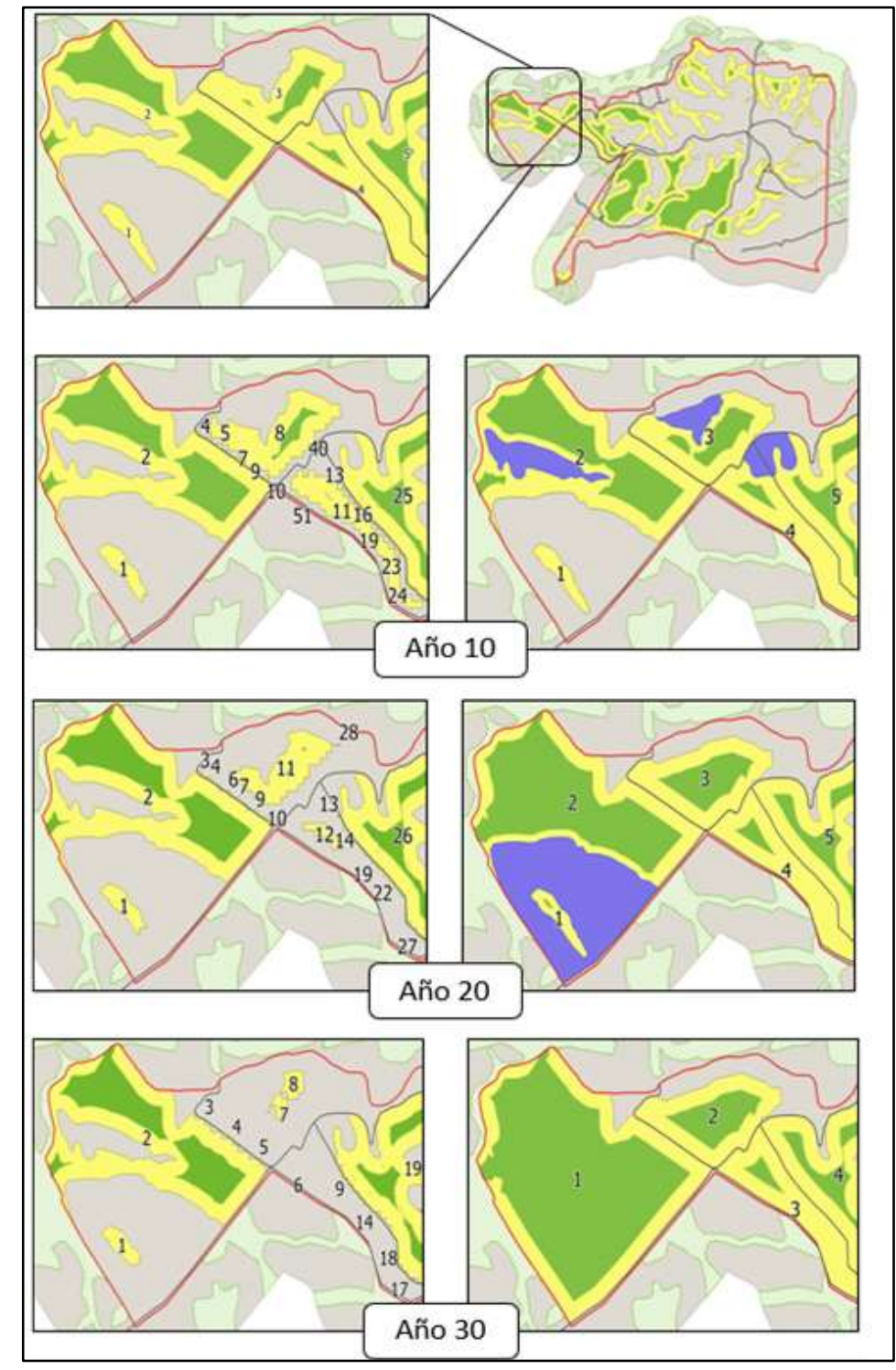

Figura 8. Acercamiento a una Zona que Muestra la Fragmentación en 30 Años

Respecto del efecto borde, (Cuadro 6) la condición inicial solo cuenta con el $28 \%$ de la superficie sin efecto borde (100 ha sobre 356 ha totales), mientras que el paisaje de referencia indica un potencial del $70 \%$ de superficie de bosque que podría estar sin efecto borde (588 ha sobre 848 ha totales de bosques 
potenciales). Es interesante el hecho que el bosque de borde es semejante entre la condición inicial y la referencia, con una diferencia de 4 ha solamente.

En 30 años en el escenario sin plan el bosque sin efecto borde se reduce en un $3 \%$ debido a la deforestación. Con plan en cambio, se recupera un $90 \%$ de la superficie a la condición sin efecto borde. Esta ganancia comparada con el paisaje de referencia significa que el Plan de Ordenación Forestal alcanzaría un $32 \%$ de la superficie potencial sin efecto borde (190 ha sobre las 588 ha sin efecto borde en el paisaje de referencia).

Cuadro 6. Relación Entre el Bosque Con Efecto del Borde y el que Está Libre del Efecto, y su Variación En 30 Años, Con y Sin POF

\begin{tabular}{|c|c|c|c|c|c|c|}
\hline \multirow{3}{*}{ Condición } & \multicolumn{6}{|c|}{$\begin{array}{l}\text { Superficies } \\
\text { (ha) }\end{array}$} \\
\hline & \multicolumn{3}{|c|}{ Bosque Con Efecto Borde } & \multicolumn{3}{|c|}{ Bosque Sin Efecto Borde } \\
\hline & Con Plan & Sin Plan & Referencia & Con Plan & Sin Plan & Referencia \\
\hline Año 0 & 256 & 256 & 260 & 100 & 100 & 588 \\
\hline Año 10 & 240 & 243 & & 115 & 98 & \\
\hline Año 20 & 239 & 231 & & 153 & 98 & \\
\hline Año 30 & 254 & 219 & & 190 & 97 & \\
\hline
\end{tabular}

\section{A Escala de Bosque}

En el análisis de captura de $\mathrm{CO}_{2}$ eq fue posible construir tres análisis de comparación: la evolución de captura de $\mathrm{CO}_{2}$ eq sin plan, que corresponde al nivel de referencia según la ENCCRV y que incluye una deforestación proyectada en el tiempo. El segundo análisis es la captura con plan solo por efecto del manejo del bosque con más de $50 \%$ de cobertura y la captura de las zonas enriquecidas por sí solas (Cuadro 7 y Figura 9).

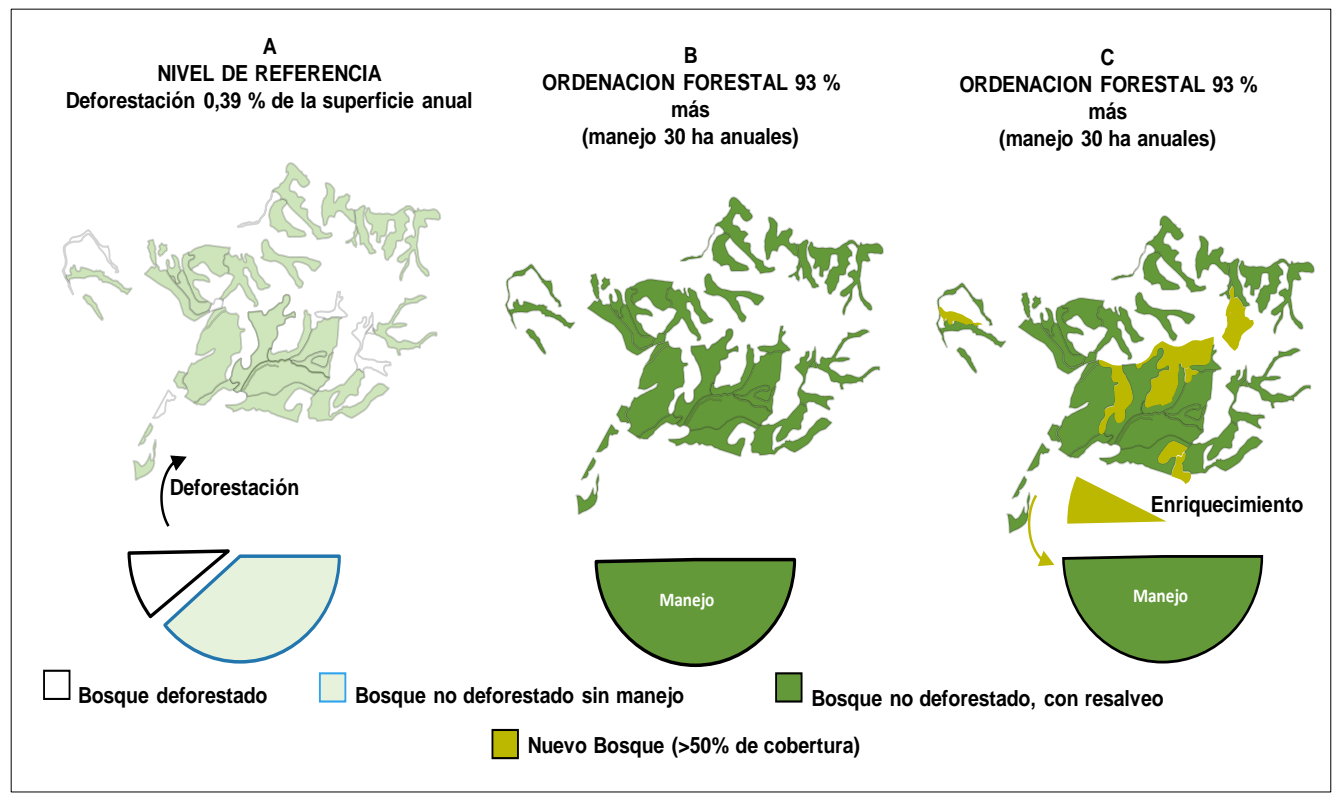

Figura 9. Diferentes Escenarios Construidos para Estimar la Captura de $\mathrm{CO}_{2} \mathrm{eq}$

Se debe destacar que la diferencia entre el escenario sin plan de ordenación y el con plan está determinada por la tasa de superficie intervenida anualmente, y esto a su vez se condiciona por los parámetros de ordenación forestal que, para este caso, quedó fijada en 30 ha (Cuadro 1).

Solo el manejo de los bosques con cobertura mayor a 50\% (OF en el Cuadro 7) aumenta a casi el doble respecto de las tasas captura de $\mathrm{CO}_{2}$ eq de la condición sin manejo (Figura 10). 
Las zonas enriquecidas en cambio, solo agregan un $15 \%$ de captura respecto de la captura sin plan y esta ganancia comienza a sumarse levemente desde el segundo periodo (desde año 10 en adelante).

Cuadro 7. Captura de $\mathrm{CO}_{2} \mathrm{eq}$ en los Diferentes Escenarios

\begin{tabular}{|c|c|c|c|c|c|c|c|c|c|c|c|c|c|}
\hline \multirow{3}{*}{ Etapa } & \multicolumn{9}{|c|}{ Captura en los Tres Escenarios } & \multicolumn{4}{|c|}{ Ganancia } \\
\hline & \multicolumn{3}{|c|}{$\begin{array}{l}\text { Sin } \\
\text { Plan }\end{array}$} & \multicolumn{3}{|c|}{$\begin{array}{c}\text { Solo Ordenación } \\
\text { Forestal }\end{array}$} & \multicolumn{3}{|c|}{$\begin{array}{c}\text { Solo } \\
\text { Enriquecimiento }\end{array}$} & \multicolumn{2}{|c|}{$\begin{array}{l}\text { Total } \\
\text { (Mt) }\end{array}$} & \multicolumn{2}{|c|}{ (\%) } \\
\hline & (t/ha) & $\begin{array}{l}\text { Sup } \\
\text { (ha) }\end{array}$ & $\begin{array}{l}\text { Total } \\
\text { (Mt) }\end{array}$ & (t/ha) & $\begin{array}{l}\text { Sup } \\
\text { (ha) }\end{array}$ & $\begin{array}{c}\text { Total } \\
\text { (Mt) }\end{array}$ & (t/ha) & $\begin{array}{l}\text { Sup } \\
\text { (ha) })^{3}\end{array}$ & $\begin{array}{l}\text { Total } \\
\text { (Mt) }\end{array}$ & OF & Enriq & OF & Enriq \\
\hline Año 0 & 135 & 356 & 48 & 135 & 356 & 48 & - & - & - & - & - & - & - \\
\hline Año 10 & 182 & 343 & 62 & 198 & 356 & 70 & - & - & - & 8 & - & 13 & - \\
\hline Año 20 & 219 & 330 & 72 & 312 & 356 & 111 & 81,2 & 37 & 3 & 39 & 3 & 54 & 4 \\
\hline Año 30 & 243 & 317 & 77 & 416 & 356 & 148 & 126,5 & 89 & 11 & 71 & 11 & 93 & 15 \\
\hline
\end{tabular}

${ }^{1}$ La superficie se reduce por deforestación.

${ }^{2}$ La OF suprime la deforestación por tanto la superficie es constante.

${ }^{3}$ Las nuevas forestaciones son bosque solo 13 años después de la instalación.

\section{Evaluación Financiera}

Se usaron costos de las dos actividades, resalveo y enriquecimiento, promedios que se pagaron en los cuatro predios del proyecto APL (Cuadro 8). El valor de la confección del POF anual se prorratea por 10 años, dado que esa es su duración.

Cuadro 8. Costos Unitarios y Anuales por Cada Actividad Realizada

\begin{tabular}{lccrrr}
\cline { 2 - 5 } & \multicolumn{2}{c}{ Valor Unitario } & \multicolumn{2}{c}{ Total Anual } \\
\cline { 2 - 5 } & $\mathbf{( M \$ / h a )}$ & $\begin{array}{c}\text { Sup } \\
\text { (ha/año) }\end{array}$ & (M\$/año) & (US\$/año) \\
\hline Resalveo & 1.200 & 30 & 36.000 & 49.931 \\
Enriquecimiento & 2.500 & 5 & 12.500 & 17.337 \\
POF & 6 & $(695)$ & 417 & 578 \\
\hline Total & & & 48.917 & 67.846 \\
\hline
\end{tabular}

El rendimiento financiero de la captura de $\mathrm{CO}_{2} \mathrm{eq}$ (Cuadro 9) se determinó por cada periodo, separando las acciones de solo silvicultura y de enriquecimiento, según se muestra en la Cuadro 7.

Cuadro 9. Rendimiento Financiero de la Acumulación Adicional de $\mathrm{CO}_{2}$ eq Totales por Periodo y Total se Separa en el Análisis la Silvicultura del Enriquecimiento.

\begin{tabular}{|c|c|c|c|c|c|c|}
\hline \multirow{3}{*}{ Periodo } & \multicolumn{2}{|c|}{$\begin{array}{c}\text { Captura Adicional } \\
\mathrm{CO}_{2} \mathrm{eq}\end{array}$} & \multicolumn{4}{|c|}{$\begin{array}{c}\text { Costo Unitario Adicional } \\
\mathrm{CO}_{2} \mathrm{eq}\end{array}$} \\
\hline & \multirow[t]{2}{*}{ OF } & \multirow[t]{2}{*}{ Enriq. } & \multicolumn{2}{|c|}{ Enriq. } & \multicolumn{2}{|c|}{ Costo Enriquecimiento } \\
\hline & & & $(\$ / t)$ & (US\$/t) & $(\$ / t)$ & (US\$/t) \\
\hline 0 & & & & & & \\
\hline 10 & 8.052 & - & $44.709,4$ & 62 & & \\
\hline 20 & 38.869 & 3.038 & $9.261,8$ & 13 & 82.296 & 114 \\
\hline 30 & 71.498 & 11.218 & $5.035,1$ & 7 & 11.143 & 15 \\
\hline totales & 118.419 & 14.255 & & & & \\
\hline \multicolumn{3}{|c|}{ Unitario } & & & & \\
\hline Sup (ha) & $356^{1}$ & $150^{2}$ & & & & \\
\hline Totales en 30 años ( $t / h a)$ & 333 & 95 & & & & \\
\hline
\end{tabular}

Los costos de enriquecimiento del periodo 20 incluyen los pagos del primer y del segundo periodo.

Al final del periodo analizado (30 años), el POF con solo silvicultura arrojó un costo de 7 US\$/t de $\mathrm{CO}_{2} e q$ adicional a la que captura el bosque sin plan, siendo la mitad del costo de solo los enriquecimientos (Figura 10). 


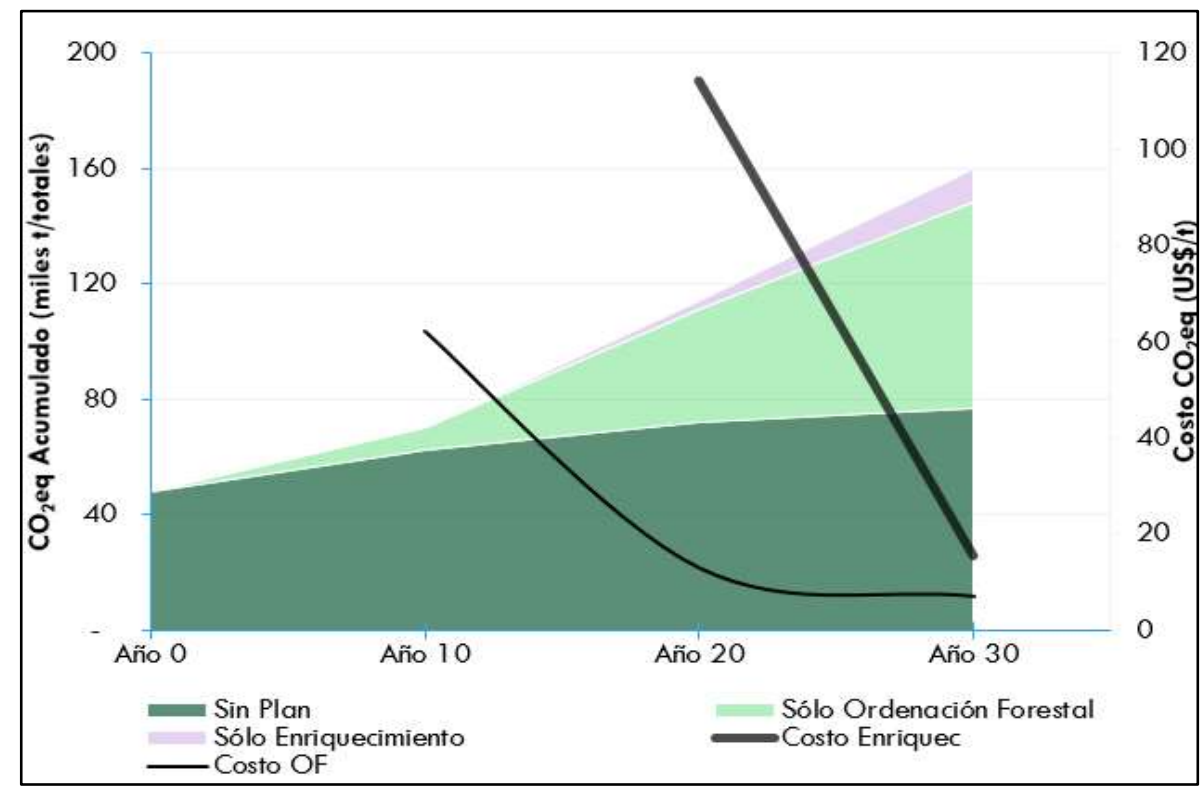

Figura 10. Acumulación de $\mathrm{CO}_{2}$ eq Durante los Tres Periodos Analizados Separando solo la Ejecución de Silvicultura y Solo el Enriquecimiento

Los costos unitarios de la captura de $\mathrm{CO}_{2}$ eq debidas a solo manejo se reducen en el tiempo debido a que las áreas manejadas van acumulando carbono adicional al escenario sin manejo, con una tendencia exponencial, en forma continua en el tiempo sin requerir gastos cada año, salvo al momento de la segunda intervención, y la acumulación de nueva superficie bajo manejo. Esto significa que el gasto anual de manejo es constante, mientras que el monto de captura adicional crece cada año. En los últimos años, cercanos al año 30 , cesa este proceso, dado que todo el bosque está manejado, y la curva se estabiliza con una pendiente en torno a cero.

Los costos unitarios de la captura de $\mathrm{CO}_{2}$ eq debidas a solo enriquecimiento también se reducen por el aumento de la superficie que comienza a capturar y no cambia de pendiente, dado a que en este escenario se hace enriquecimiento hasta el último año. Así, podría ocurrir que ambos costos unitarios se hubieran igualado en el futuro más allá de 30 años.

\section{DISCUSIÓN}

Los valores de mortalidad promedio obtenidos de los ensayos de resalveo son similares a los obtenidos por Mosquera et al. (2009) y Clark y Clark (1995). De igual manera, los crecimientos diametrales están dentro de los rangos que presenta Donoso (2015). Los costos por plantación forestal y restauración por manejo son similares a los propuestos por Vergara et al. (2016) para América latina y el Caribe.

Los efectos del plan de ordenación forestal, con un enriquecimiento destinado a unir los fragmentos del bosque existente y simultáneamente la aplicación de resalveos que mejoran la vigorosidad del bosque, y ambas acciones planificadas en un horizonte de largo plazo, resumen la esencia de integralidad que contiene la ordenación forestal que define la ENCCRV (Ministerio de Agricultura, 2016), y la definición teórica de su aplicación (Cruz, 2020). Por tanto, los efectos deben analizarse también integralmente, además de unitariamente, en cada rodal. En este sentido, el enriquecimiento lograría en 30 años dos importantes efectos ecosistémicos. El primero detener la fragmentación, e incluso reducirla al $74 \%$ respecto del número de fragmentos originales (el bosque abandonado y sin plan aumenta de 19 a 54 fragmentos, un $274 \%$ ). El segundo efecto es un aumento de casi al doble del bosque libre del efecto borde en el mismo periodo. Ambos procesos, debieran mejorar notoriamente la capacidad de resilencia y autoregulación del bosque futuro (Peña et al., 2005), sin la subsidiariedad del ser humano. Estos resultados, permiten plantear que los mejores efectos en la restauración del paisaje forestal se obtienen 
cuando la planificación incluye tanto la silvicultura aplicada a los bosques, como la recuperación de bosques.

La evaluación de un paisaje de referencia permite agregar métrica a los beneficios del esfuerzo de restauración. En este caso, por ejemplo, la ejecución del POF lograría aumentar el área sin efecto borde solo en un $32 \%$ respecto del potencial (190 hectáreas con plan de 588 hectáreas que se estimaron en el paisaje de referencia), pero se acerca mucho a los mínimos fragmentos potenciales (con plan se reducen a 14 de los 9 que deberían existir, según el paisaje de referencia). Evidentemente estas cifras están condicionadas a las posibilidades financieras del ejecutor del plan para invertir en nuevas áreas forestadas.

El aumento de la productividad provocada por el manejo en el largo plazo es coincidente con varias experiencias de silvicultura comparada con el crecimiento sin manejo, analizadas y compiladas por Dieler et. al. (2017) para los bosques europeos. En este caso de estudio el aumento fue casi al doble en 30 años. No obstante, la aplicación del parámetro de ordenación forestal que restringe el manejo solo a 30 hectáreas anuales, provoca que la captura de $\mathrm{CO}_{2}$ eq fuera baja en el periodo inicial, pero ascendente en los siguientes periodos. Entonces, el beneficio de la restauración bajo un marco de ordenación forestal no solo depende de recursos financieros, sino que también de los máximos que imponen los criterios de rendimiento sostenido.

El costo de manejo llevado a captura adicional de $\mathrm{CO}_{2}$ eq, respecto del escenario sin plan, a los 30 años es superior al precio promedio del mercado para el 2019, de 4,3 US\$/t (Donofrío et al., 2020), y la situación es peor en el caso de solo enriquecimiento en 30 años.

No obstante, de cumplirse las tendencias que proponen que un precio que activaría cambios en las conductas de deforestación a escala mundial para las próximas décadas debería oscilar entre 10 a 30 US\$/t de $\mathrm{CO}_{2}$ eq (Labbate et al., 2021), los resultados proyectados permitirían afirmar que sería factible el financiamiento de la restauración mediante ordenación forestal a través de mecanismos del mercado voluntario de carbono.

Dado el énfasis que se ha hecho en este estudio de usar métrica en proyectos de restauración de largo plazo como el que se ha analizado, se presenta en el Cuadro 10 una síntesis del desempeño del proyecto en 30 años.

CUADRO $\mathrm{N}^{\circ} 10$

Síntesis del Desempeño del POF en 30 Años

\begin{tabular}{|c|c|c|}
\hline Parámetro de Análisis & Variación Gráfica & Variación Numérica \\
\hline Fragmentación & 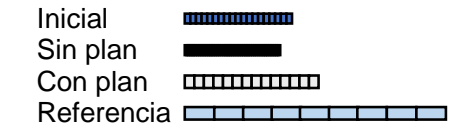 & $\begin{array}{r}19 \text { fragmentos } \\
52 \text { fragmentos } \\
14 \text { fragmentos } \\
9 \text { fragmentos }\end{array}$ \\
\hline $\begin{array}{l}\text { Bosque sin efecto Borde } \\
\text { (SEB) }\end{array}$ & $\begin{array}{l}\text { Inicial } \square \\
\text { Sin plan } \square \\
\text { Con plan } \\
\text { Referencia }\end{array}$ & $\begin{array}{l}100 \text { ha SEB } \\
92 \text { ha SEB } \\
190 \text { ha SEB } \\
588 \text { ha SEB }\end{array}$ \\
\hline Captura de $\mathrm{CO}_{2} \mathrm{eq}$ & $\begin{array}{l}\text { Inicial } \\
\text { Sin plan } \\
\text { Con plan }\end{array}$ & $\begin{array}{r}48 \text { mil t } \mathrm{CO}_{2} \mathrm{eq} \\
77 \text { mil t } \mathrm{CO}_{2} \mathrm{eq} \\
160 \text { mil t } \mathrm{CO}_{2} \mathrm{eq}\end{array}$ \\
\hline
\end{tabular}

\section{CONCLUSIONES Y RECOMENDACIONES}

La aplicación del POF para la restauración combinando aumento de bosques y recuperación con resalveo lograría casi duplicar el bosque sin efecto borde y reducir la fragmentación al $74 \%$ respecto de la 
condición inicial, mejorando la resiliencia del bosque, en un periodo de 30 años. Esta ganancia, comparada con el paisaje de referencia (bosque restaurado potencial), es muy significativa respecto de la fragmentación, pero solo de un $32 \%$ de la superficie sin efecto borde potencial que debería tener el caso de estudio.

EI POF aplicado logró más que duplicar la captura de $\mathrm{CO}_{2}$ eq en 30 años, aunque la ganancia se debió en un $93 \%$ solo a la mejora de los bosques por el resalveo. Así, desde el punto de vista de la restauración, el enriquecimiento, o su equivalente en forestación, no sería relevante como sumidero, aunque tendría mucho valor si es integrado para aumentar y dar más resiliencia al bosque.

La aplicación de parámetros de ordenación determina el ritmo por el cual se maneja el bosque y podría ser negativo para casos de restauración, dado que, de aumentarse la superficie manejada cada año, sería posible que el bosque total aumentara más rápidamente su ritmo de crecimiento y de recuperación. Si se considera, además, que estos bosques están siendo afectados por el calentamiento global de forma significativa, sería recomendable estudiar algún parámetro para la ordenación forestal que permita aumentar las superficies a manejar en cada periodo.

El modelo arroja un costo unitario de $\mathrm{CO}_{2}$ eq que se reduce cada año por efecto acumulativo del bosque manejado, que termina estabilizándose en 7 US $\$ / t$ para el caso del resalveo. Para el caso de enriquecimiento, en 30 años alcanzó los 15 US\$/t, con una clara tendencia a la baja.

\section{REFERENCIAS}

ASCC. (2016). Manejo sustentable del bosque nativo mediterráneo, región de Valparaíso. En: https://www.ascc.cl/resources/uploads/documentos/archivos/512/apl_manejo_sustentable_del_bosque_nativo_mediterraneo _-_region_de_valparaiso.pdf. Consulta: 10 abril, 2021.

Clark, D. \& Clark, D. (1995). Abundance, growth and mortality of very large trees in neotropical lowland rain forest. Forest Ecology and Management, Volumen 80, pp. 235-244. https://doi.org/10.1016/0378-1127(95)03607-5

CONAF. (2016). Nivel de referencia de emisiones forestales / Nivel de referencia forestal subnacional de Chile. Santiago.

CONAF. (1997). Plan de ordenación de la reserva nacional Malleco. Santiago.

Cruz, P. \& Gorospe, J. (2019). Propuesta de paisaje de referencia para evaluar desempeño de índices del paisaje. Caso del parque Tagua Tagua, Chile. Madera y Bosque, 25(1), 1-19. https://doi.org/10.21829/myb.2019.2511757

Cruz, P. (2020). Principios de ordenación forestal para Chile. Santiago.

Cruz, P., Cid, F., Rivas., Neira, E. \& Ladrón de Guevara, J. (2012). Evaluación del Fondo de Conservación, Recuperación y Manejo Sustentable del Bosque Nativo. CONAF. Santiago: Agrupación de Ingenieros Forestal por el Bosque Nativo. En: https://www.academia.edu/15487696/Evaluaci\%C3\%B3n_de_la_Ley_No20_283_sobre_recuperaci\%C3\%B3n_del_bosque_ nativo_y_fomento_forestal_para_la_Subsecretar\%C3\%ADa_de_Agricultura. Consulta: 9 abril, 2021

Cruz, P., Solís, R., Díaz, S., Rojas, A. \& Ramos, F. (2001). Plan de ordenación forestal. primera versión para la ordenación del área de plantaciones. CONAF. Corporación Nacional Forestal.

Del Río, M., Montes, F. \& Cañellas, I.M. (2003). Índices de diversidad estructural en masas forestales. Invest. Agrar.: Sist. Recur. For., 12(1): 159-176.

Dieler, J., Uhl, E., Biber, P., Müller, J., Rötzer, T. \& Pretzsch, H. (2017). Effect of forest stand management on species composition, structural diversity, and productivity in the temperate zone of Europe. Eur. J. Forest Res., 136. Pp: $739-766$. https://doi.org/10.1007/s10342-017-1056-1

Donofrío, S., Maguire, P., Zwick, S. \& Merry, W. (2020). Voluntary carbon and the post-pandemic recovery. En: https://app.hubspot.com/documents/3298623/view/88656172?accessld=b01f32. Consulta: 9 abril, 2021.

Donoso, C. (2015). Estructura y dinámica de los bosques del cono sur de América. Santiago: Universidad Mayor.

IPCC. (2003). Good practice guidance for land-use change and forestry. Intergovernmental Panel on Climate Change. Hayama, Japan.

IPCC. (2006). Directrices del IPCC de 2006 para los inventarios nacionales de gases de efecto invernadero. WMO, UNEP. Intergovernmental Panel on Climate Change.

Labbate, G., Edwards, R., Lubowsky, R. \& Coello, J. (2021). Could 2021 be a turning point for forests and climate change?. En: https://www.weforum.org/agenda/2021/02/2021-turning-point-forests-climate-change. Consulta 9 de abril 2021.

Lindenmayer, D., Franklin, J. \& Fischer, J. (2006). General management principles and a checklist of strategies to guide forest biodiversity conservation. Biological Conservation, 131. Pp: 433-445. https://doi.org/10.1016/..biocon.2006.02.019 
Masera, O., Garza-Caligaris, J., Kanninen, M., Karjalainen, T., Liksi, J., Nabuurs, G., Pussinen, A. et al. (2003). Modeling carbon sequestration in afforestation, agroforestry and forest management projects: the CO2FIX V.2 approach. Ecological Modelling, 164. Pp: 177-199. https://doi.org/10.1016/S0304-3800(02)00419-2

Ministerio de Agricultura. (2008). Ley Sobre Recuperación del Bosque Nativo y Fomento Forestal.

Ministerio de Agricultura. (2016). Estrategia Nacional de Cambio Climático y Recursos Vegetacionales. MINAGRI Santiago.

Mosquera, H., Rengifo, R. \& Ramos, Y. (2009). Mortalidad y reclutamiento de árboles en un bosque pluvial tropical de Chocó (Colombia). Rev. Fac. Nal. Agr. Medellín, 62(1): 4855-4868.

Murcia, C. (1995). Edge effects in fragmented forests: implications for conservation. Trends in Ecology and Evolution, 10(2): 58-62. https://doi.org/10.1016/S0169-5347(00)88977-6

Oterra, U. (2014). Elaboración de insumos técnicos y metodológicos para el desarrollo de la tipología de proyectos forestales de captura de carbono por medio de la restauración de bosques mediterráneos. Corporación Nacional Forestal. Santiago.

Peña, J., Monroy, F., Álvarez, F. \& Socorro, M. (2005). Uso del efecto borde de la vegetación para la restauración ecológica del bosque tropical. Revista Especializada en Ciencias Químico-Biológicas, 8(2): 91-98.

Reynolds, M., Burk, T. \& Huang, W. (1988). Goodness-of-fit test and model selection procedures for diameter distribution model. Forest Science, 34(2): 73-399.

Rivera, H., Rudlof, A. \& Cruz, P. (2002). Plan de Ordenación de la Reserva Nacional Valdivia. Santiago: CONAF/GTZ.

Rothermel, H. (2002). Economía del manejo sustentable. Universidad Mayor. Santiago.

Schulte, L., Mitchell, R., Hunter, M., Franklin, J., Mclntyre, K. \& Palik, B. (2006). Evaluating the conceptual tools for forest biodiversity conservation and their implementation in U.S. Forest ecology and management, 232, 1-11. https://doi.org/10.1016/i.foreco.2006.05.009

Vogelmann, J. E. (1995). Assessment of forest fragmentation in southern New England using remote sensing and geographic information systems technology. Conservation Biology, 9(2), 439-449. https://doi.org/10.1046/j.1523-1739.1995.9020439.x 